\title{
ReSEARChArticle
}

\section{Effect of hormonal treatments on haploid formation and in vitro haploid regeneration in wheat $x$ maize system}

\author{
USHA PANT AND V.K. KHANNA
}

\section{SUMMARY}

Haploids are useful for basic studies on inter-genomic relationship, molecular studies and in practical breeding. In the present investigation post pollination treatment with different growth regulators and their combinations were analyzed. Twenty nine wheat $F_{1}$ 's and three maize parents were utilized to obtained haploid embryos. Three different hormonal treatments were designed to observe their effect on different parameters in wheat-maize haploid system. Out of three treatments, combination of GA3 and 2,4-D showed highly significant effect on caryopsis formation frequency (64.40), embryo formation frequency (18.84), embryo germination frequency (55.82) and haploid regeneration frequency (36.51). The growth pattern of haploid embryos on nutrient medium was quite different. The differential response of haploid embryos on same nutrient medium might be because of residual effect of different growth regulators.

Key Words : Wheat x maize, Haploid embryo, Hormonal treatment, Residual effect

How to cite this article : Pant, Usha and Khanna, V.K. (2017). Effect of hormonal treatments on haploid formation and in vitro haploid regeneration in wheat x maize system. Internat. J. Plant Sci., 12 (2): 234-239, DOI: 10.15740/HAS/IJPS/12.2/234239.

Article chronicle : Received : 23.04.2017; Revised : 25.05.2017; Accepted : 15.06.2017

Email : ushapantgpb@gmail.com 